\title{
Strong convergence of an implicit iteration process for a finite family of strictly asymptotically pseudocontractive mappings
}

\author{
Gurucharan Singh Saluja \\ Department of Mathematics \& Information Technology, \\ Govt. Nagarjuna P.G. College of Science, Raipur (C.G.). \\ email: saluja_19630rediffmail.com \\ and \\ Hemant Kumar Nashine \\ Department of Mathematics, \\ Disha Institute of Management and Technology, \\ Satya Vihar, Vidhansabha-Chandrakhuri Marg \\ Mandir Hasaud, Raipur-492101(Chhattisgarh), India. \\ email: hnashine@rediffmail.com, nashine_o9@rediffmail.com
}

\begin{abstract}
In this paper, we establish the strong convergence theorems for a finite family of $k$ strictly asymptotically pseudo-contractive mappings in the framework of Hilbert spaces. Our results improve and extend the corresponding results of Liu [5] and many others.

\section{RESUMEN}

En este trabajo, hemos establecido los teoremas de convergencia para una familia finita de asignaciones de $k$-estrictamente asintticamente pseudo-contraccin en el marco de los espacios de Hilbert. Nuestros resultados mejoran y amplan los resultados correspondientes de Liu [5] y muchos otros.
\end{abstract}


Keywords: Strictly asymptotically pseudo-contractive mapping, implicit iteration scheme, common fixed point, strong convergence, Hilbert space.

AMS Subject Classification: 47H09, 47H10.

\section{Introduction}

Let $H$ be a real Hilbert space with the scalar product and norm denoted by the symbols $\langle.,$.$\rangle and$ $\|$. $\|$ respectively, and $C$ be a closed convex subset of $H$. Let $T$ be a (possibly) nonlinear mapping from $C$ into $C$. We now consider the following classes:

(1) $T$ is contractive, i.e., there exists a constant $k<1$ such that

$$
\|T x-T y\| \leq k\|x-y\|,
$$

for all $x, y \in C$.

(2) $T$ is nonexpansive, i.e.,

$$
\|T x-T y\| \leq\|x-y\|
$$

for all $x, y \in C$.

(3) $T$ is uniformly $L$-Lipschitzian, i.e., if there exists a constant $L>0$ such that

$$
\left\|T^{n} x-T^{n} y\right\| \leq L\|x-y\|,
$$

for all $x, y \in C$ and $n \in \mathbb{N}$.

(4) $T$ is pseudo-contractive, i.e.,

$$
\langle T x-T y, j(x-y)\rangle \leq\|x-y\|^{2},
$$

for all $x, y \in C$.

(5) $T$ is strictly pseudo-contractive, i.e., there exists a constant $k \in[0,1)$ such that

$$
\|T x-T y\|^{2} \leq\|x-y\|^{2}+k\|(x-T x)-(y-T y)\|^{2},
$$


for all $x, y \in C$.

(6) $T$ is asymptotically nonexpansive [3], i.e., if there exists a sequence $\left\{r_{n}\right\} \subset[0, \infty)$ with $\lim _{n \rightarrow \infty} r_{n}=0$ such that

$$
\left\|T^{n} x-T^{n} y\right\| \leq\left(1+r_{n}\right)\|x-y\|,
$$

for all $x, y \in C$ and $n \in \mathbb{N}$.

(7) $T$ is $k$-strictly asymptotically pseudo-contractive [6], i.e., if there exists a sequence $\left\{r_{n}\right\} \subset[0, \infty)$ with $\lim _{n \rightarrow \infty} r_{n}=0$ such that

$$
\begin{aligned}
\left\|T^{n} x-T^{n} y\right\|^{2} \leq & \left(1+r_{n}\right)^{2}\|x-y\|^{2} \\
& +k\left\|\left(x-T^{n} x\right)-\left(y-T^{n} y\right)\right\|^{2}
\end{aligned}
$$

for some $k \in[0,1)$ for all $x, y \in C$ and $n \in \mathbb{N}$.

Remark 1.1 [6]: If $T$ is $k$-strictly asymptotically pseudo-contractive mapping, then it is uniformly $L$-Lipschitzian, but the converse does not hold.

Concerning the convergence problem of iterative sequences for strictly pseudocontractive mappings has been studied by several authors (see, e.g., $[2,4,7,11,12]$ ). Concerning the class of strictly asymptotically pseudocontractive mappings, Liu [5] proved the following result in Hilbert space:

Theorem 1.1(Liu [5]): Let $H$ be a real Hilbert space, let $C$ be a nonempty closed convex and bounded subset of $H$, and let $T: C \rightarrow C$ be a completely continuous uniformly $L$-Lipschitzian $\left(\lambda,\left\{k_{n}\right\}\right)$-strictly asymptotically pseudocontractive mapping such that $\sum_{n=1}^{\infty}\left(k_{n}^{2}-1\right)<\infty$. Let $\left\{\alpha_{n}\right\} \subset(0,1)$ be a sequence satisfying the following condition:

$$
0<\epsilon \leq \alpha_{n} \leq 1-\lambda-\epsilon \forall n \geq 1 \text { and some } \epsilon>0 \text {. }
$$

Then, the sequence $\left\{x_{n}\right\}$ generated from an arbitrary $x_{1} \in C$ by

$$
x_{n+1}=\left(1-\alpha_{n}\right) x_{n}+\alpha_{n} T^{n} x_{n}, \quad \forall n \geq 1
$$

converges strongly to a fixed point of $T$. 
In 2001, $\mathrm{Xu}$ and Ori [12] have introduced an implicit iteration process for a finite family of nonexpansive mappings in a Hilbert space $H$. Let $C$ be a nonempty subset of $H$. Let $T_{1}, T_{2}, \ldots, T_{N}$ be self-mappings of $C$ and suppose that $\mathcal{F}=\cap_{i=1}^{N} F\left(T_{i}\right) \neq \emptyset$, the set of common fixed points of $T_{i}, i=1,2, \ldots, N$. An implicit iteration process for a finite family of nonexpansive mappings is defined as follows, with $\left\{t_{n}\right\}$ a real sequence in $(0,1), x_{0} \in C$ :

$$
\begin{aligned}
x_{1} & =t_{1} x_{0}+\left(1-t_{1}\right) T_{1} x_{1}, \\
x_{2} & =t_{2} x_{1}+\left(1-t_{2}\right) T_{2} x_{2}, \\
& \vdots \\
x_{N} & =t_{N} x_{N-1}+\left(1-t_{N}\right) T_{N} x_{N}, \\
x_{N+1} & =t_{N+1} x_{N}+\left(1-t_{N+1}\right) T_{1} x_{N+1},
\end{aligned}
$$

which can be written in the following compact form:

$$
x_{n}=t_{n} x_{n-1}+\left(1-t_{n}\right) T_{n} x_{n}, \quad n \geq 1
$$

where $T_{k}=T_{k} \bmod N$. (Here the mod $\mathrm{N}$ function takes values in $\{1,2, \ldots, N\}$ ). And they proved the weak convergence of the process (1.9).

Very recently, Acedo and Xu [1] still in the framework of Hilbert spaces introduced the following cyclic algorithm.

Let $C$ be a closed convex subset of a Hilbert space $H$ and let $\left\{T_{i}\right\}_{i=0}^{N-1}$ be $N k$-strict pseudocontractions on $C$ such that $F=\bigcap_{i=0}^{N-1} F\left(T_{i}\right) \neq \emptyset$. Let $x_{0} \in C$ and let $\left\{\alpha_{n}\right\}$ be a sequence in $(0,1)$. The cyclic algorithm generates a sequence $\left\{x_{n}\right\}_{n=1}^{\infty}$ in the following way:

$$
\begin{aligned}
x_{1} & =\alpha_{0} x_{0}+\left(1-\alpha_{0}\right) T_{0} x_{0}, \\
x_{2} & =\alpha_{1} x_{1}+\left(1-\alpha_{1}\right) T_{1} x_{1}, \\
& \vdots \\
x_{N} & =\alpha_{N-1} x_{N-1}+\left(1-\alpha_{N-1}\right) T_{N-1} x_{N-1}, \\
x_{N+1} & =\alpha_{N} x_{N}+\left(1-\alpha_{N}\right) T_{0} x_{N},
\end{aligned}
$$

In general, $\left\{x_{n+1}\right\}$ is defined by

$$
x_{n+1}=\alpha_{n} x_{n}+\left(1-\alpha_{n}\right) T_{[n]} x_{n},
$$


where $T_{[n]}=T_{i}$ with $i=n(\bmod N), 0 \leq i \leq N-1$. They also proved a weak convergence theorem for $k$-strict pseudo-contractions in Hilbert spaces by cyclic algorithm (1.10). More precisely, they obtained the following theorem:

Theorem AX [1]: Let $C$ be a closed convex subset of a Hilbert space $H$. Let $N \geq 1$ be an integer. Let for each $0 \leq i \leq N-1, T_{i}: C \rightarrow C$ be a $k_{i}$-strict pseudo-contraction for some $0 \leq k_{i}<1$. Let $k=\max \left\{k_{i}: 1 \leq i \leq N\right\}$. Assume the common fixed point the set $\bigcap_{i=0}^{N-1} F\left(T_{i}\right)$ of $\left\{T_{i}\right\}_{i=0}^{N-1}$ is nonempty. Given $x_{0} \in C$, let $\left\{x_{n}\right\}_{n=0}^{\infty}$ be the sequence generated by the cyclic algorithm (1.10). Assume that the control sequence $\left\{\alpha_{n}\right\}$ is chosen so that $k+\epsilon<\alpha_{n}<1-\epsilon$ for all $n$ and for some $\epsilon \in(0,1)$. Then $\left\{x_{n}\right\}$ converges weakly to a common fixed point of the family $\left\{T_{i}\right\}_{i=0}^{N-1}$.

Motivated by Xu and Ori [12], Acedo and Xu [1] and some others we introduce and study the following:

Let $C$ be a closed convex subset of a Hilbert space $H$ and let $\left\{T_{i}\right\}_{i=0}^{N-1}$ be $N k$-strictly asymptotically pseudo-contractions on $C$ such that $F=\bigcap_{i=0}^{N-1} F\left(T_{i}\right) \neq \emptyset$. Let $x_{0} \in C$ and let $\left\{\alpha_{n}\right\}$ be a sequence in $(0,1)$. The implicit iteration scheme generates a sequence $\left\{x_{n}\right\}_{n=0}^{\infty}$ in the following way:

$$
\begin{aligned}
x_{1} & =\alpha_{0} x_{0}+\left(1-\alpha_{0}\right) T_{0} x_{0}, \\
x_{2} & =\alpha_{1} x_{1}+\left(1-\alpha_{1}\right) T_{1} x_{1}, \\
& \vdots \\
x_{N} & =\alpha_{N-1} x_{N-1}+\left(1-\alpha_{N-1}\right) T_{N-1} x_{N-1}, \\
x_{N+1} & =\alpha_{N} x_{N}+\left(1-\alpha_{N}\right) T_{0}^{2} x_{0}, \\
& \vdots \\
x_{2 N} & =\alpha_{2 N-1} x_{2 N-1}+\left(1-\alpha_{2 N-1}\right) T_{N-1}^{2} x_{2 N-1}, \\
x_{2 N+1} & =\alpha_{2 N} x_{2 N}+\left(1-\alpha_{2 N}\right) T_{0}^{3} x_{0},
\end{aligned}
$$

In general, $\left\{x_{n}\right\}$ is defined by

$$
x_{n+1}=\alpha_{n} x_{n}+\left(1-\alpha_{n}\right) T_{[n]}^{s} x_{n},
$$

where $T_{[n]}^{s}=T_{n(\bmod N)}^{s}=T_{i}^{s}$ with $n=(s-1) N+i$ and $i \in I=\{0,1, \ldots, N-1\}$.

The aim of this paper is to establish strong convergence theorems of implicit iteration process (1.11) for a finite family of $k$-strictly asymptotically pseudo-contraction mappings in Hilbert 
spaces. Our results extend the corresponding results of Liu [5] and many others.

In the sequel, we will need the following lemmas.

Lemma 1.1: Let $H$ be a real Hilbert space. There holds the following identities:

(i) $\|x-y\|^{2}=\|x\|^{2}-\|y\|^{2}-2\langle x-y, y\rangle \quad \forall x, y \in H$.

(ii) $\|t x+(1-t) y\|^{2}=t\|x\|^{2}+(1-t)\|y\|^{2}-t(1-t)\|x-y\|^{2}$,

$\forall t \in[0,1], \forall x, y \in H$.

(iii) If $\left\{x_{n}\right\}$ be a sequence in $H$ weakly converges to $z$, then

$$
\limsup _{n \rightarrow \infty}\left\|x_{n}-y\right\|^{2}=\limsup _{n \rightarrow \infty}\left\|x_{n}-z\right\|^{2}+\|z-y\|^{2} \quad \forall y \in H
$$

Lemma 1.2 [9]: Let $\left\{a_{n}\right\}_{n=1}^{\infty},\left\{\beta_{n}\right\}_{n=1}^{\infty}$ and $\left\{r_{n}\right\}_{n=1}^{\infty}$ be sequences of nonnegative real numbers satisfying the inequality

$$
a_{n+1} \leq\left(1+r_{n}\right) a_{n}+\beta_{n}, \quad n \geq 1
$$

If $\sum_{n=1}^{\infty} r_{n}<\infty$ and $\sum_{n=1}^{\infty} \beta_{n}<\infty$, then $\lim _{n \rightarrow \infty} a_{n}$ exists. If in addition $\left\{a_{n}\right\}_{n=1}^{\infty}$ has a subsequence which converges strongly to zero, then $\lim _{n \rightarrow \infty} a_{n}=0$.

\section{Main Results}

Theorem 2.1: Let $C$ be a closed convex subset of a Hilbert space $H$. Let $N \geq 1$ be an integer. Let for each $0 \leq i \leq N-1, T_{i}: C \rightarrow C$ be $N k_{i}$-strictly asymptotically pseudo-contraction mappings for some $0 \leq k_{i}<1$ and $\sum_{n=1}^{\infty} r_{n}<\infty$. Let $k=\max \left\{k_{i}: 0 \leq i \leq N-1\right\}$ and $r_{n}=\max \left\{r_{n_{i}}: 0 \leq i \leq N-1\right\}$. Assume that $F=\bigcap_{i=0}^{N-1} F\left(T_{i}\right) \neq \emptyset$. Given $x_{0} \in C$, let $\left\{x_{n}\right\}_{n=0}^{\infty}$ be the sequence generated by an implicit iteration scheme (1.11). Assume that the control sequence $\left\{\alpha_{n}\right\}$ is chosen so that $k<\alpha_{n}<1$ for all $n$ and $\sum_{n=0}^{\infty}\left(\alpha_{n}-k\right)\left(1-\alpha_{n}\right)=\infty$. Then the iterative sequence $\left\{x_{n}\right\}$ has the following properties: 
(1) $\lim _{n \rightarrow \infty}\left\|x_{n}-p\right\|$ exists for each $p \in F$,

(2) $\lim _{n \rightarrow \infty} d\left(x_{n}, F\right)$ exists,

(3) $\liminf \operatorname{in}_{n \rightarrow \infty}\left\|x_{n}-T_{[n]}^{s} x_{n}\right\|=0$,

(4) the sequence $\left\{x_{n}\right\}_{n=0}^{\infty}$ converges strongly to a common fixed point $p \in F$ if and only if

$$
\liminf _{n \rightarrow \infty} d\left(x_{n}, F\right)=0 .
$$

Proof: We divide the proof of Theorem 2.1 into three steps.

(I) First, we proof the conclusions (1)and (2).

For any $p \in F$, it follows from (1.11) and Lemma 1.1(ii), we note that

$$
\begin{aligned}
\left\|x_{n+1}-p\right\|^{2}= & \left\|\alpha_{n} x_{n}+\left(1-\alpha_{n}\right) T_{[n]}^{s} x_{n}-p\right\| \\
= & \left\|\alpha_{n}\left(x_{n}-p\right)+\left(1-\alpha_{n}\right)\left(T_{[n]}^{s} x_{n}-p\right)\right\| \\
\leq & \alpha_{n}\left\|x_{n}-p\right\|^{2}+\left(1-\alpha_{n}\right)\left\|T_{[n]}^{s} x_{n}-p\right\|^{2} \\
& -\alpha_{n}\left(1-\alpha_{n}\right)\left\|x_{n}-T_{[n]}^{s} x_{n}\right\|^{2} \\
\leq & \alpha_{n}\left\|x_{n}-p\right\|^{2}+\left(1-\alpha_{n}\right)\left[\left(1+r_{n}\right)^{2}\left\|x_{n}-p\right\|^{2}\right. \\
& \left.+k\left\|x_{n}-T_{[n]}^{s} x_{n}\right\|^{2}\right]-\alpha_{n}\left(1-\alpha_{n}\right)\left\|x_{n}-T_{[n]}^{s} x_{n}\right\|^{2} \\
\leq & {\left[\alpha_{n}\left(1+r_{n}\right)^{2}+\left(1-\alpha_{n}\right)\left(1+r_{n}\right)^{2}\right]\left\|x_{n}-p\right\|^{2} } \\
& -\left(\alpha_{n}-k\right)\left(1-\alpha_{n}\right)\left\|x_{n}-T_{[n]}^{s} x_{n}\right\|^{2} \\
\leq & \left(1+r_{n}\right)^{2}\left\|x_{n}-p\right\|^{2}-\left(\alpha_{n}-k\right)\left(1-\alpha_{n}\right)\left\|x_{n}-T_{[n]}^{s} x_{n}\right\|^{2} \\
\leq & \left(1+d_{n}\right)\left\|x_{n}-p\right\|^{2}-\left(\alpha_{n}-k\right)\left(1-\alpha_{n}\right)\left\|x_{n}-T_{[n]}^{s} x_{n}\right\|^{2}
\end{aligned}
$$

where $d_{n}=r_{n}^{2}+2 r_{n}$, since $\sum_{n=1}^{\infty} r_{n}<\infty$ thus $\sum_{n=1}^{\infty} d_{n}<\infty$ and since $k<\alpha_{n}<1$, we get

$$
\left\|x_{n+1}-p\right\|^{2} \leq\left(1+d_{n}\right)\left\|x_{n}-p\right\|^{2}
$$

and therefore 


$$
\left\|x_{n+1}-p\right\| \leq\left(1+d_{n}\right)^{1 / 2}\left\|x_{n}-p\right\|
$$

Since $\sum_{n=1}^{\infty} d_{n}<\infty$, it follows from Lemma 1.2, we know that $\lim _{n \rightarrow \infty}\left\|x_{n}-p\right\|$ exists for each $p \in F$. So that there exists $K>0$ such that $\left\|x_{n}-p\right\| \leq K$ for all $n \geq 1$. Consequently, we obtain from (2.3) that

$$
\begin{aligned}
\left\|x_{n+1}-p\right\| & \leq\left(1+d_{n}\right)^{1 / 2}\left\|x_{n}-p\right\| \\
& \leq\left(1+d_{n}\right)\left\|x_{n}-p\right\| \\
& \leq\left\|x_{n}-p\right\|+K d_{n} .
\end{aligned}
$$

It follows from (2.4) that

$$
d\left(x_{n+1}, F\right) \leq\left(1+d_{n}\right) d\left(x_{n}, F\right), \quad \forall n \geq 1
$$

so that it again follows from Lemma 1.2 that $\lim _{n \rightarrow \infty} d\left(x_{n}, F\right)$ exists.

The conclusions (1)and (2) are proved.

(II) The proof of conclusion (3).

It follows from (2.1) that

$$
\begin{aligned}
\left\|x_{n+1}-p\right\|^{2} \leq & \left(1+d_{n}\right)\left\|x_{n}-p\right\|^{2} \\
& -\left(\alpha_{n}-k\right)\left(1-\alpha_{n}\right)\left\|x_{n}-T_{[n]}^{s} x_{n}\right\|^{2}
\end{aligned}
$$

where $d_{n}=r_{n}^{2}+2 r_{n}$, since $\sum_{n=1}^{\infty} r_{n}<\infty$ thus $\sum_{n=1}^{\infty} d_{n}<\infty$ and since $k<\alpha_{n}<1$, we get

$$
\left\|x_{n+1}-p\right\|^{2} \leq\left(1+d_{n}\right)\left\|x_{n}-p\right\|^{2}
$$

that means the sequence $\left\{\left\|x_{n}-p\right\|\right\}$ is decreasing. Now, since $\sum_{n=1}^{\infty} d_{n}<\infty$ it follows that $\prod_{i=1}^{\infty}\left(1+d_{i}\right)<\infty$, from (2.6), we have

$$
\begin{aligned}
\sum_{n=0}^{\infty}\left(\alpha_{n}-k\right)\left(1-\alpha_{n}\right)\left\|x_{n}-T_{[n]}^{s} x_{n}\right\|^{2} & \leq \prod_{i=1}^{\infty}\left(1+d_{i}\right)\left\|x_{0}-p\right\|^{2} \\
& <\infty .
\end{aligned}
$$


Since $\sum_{n=0}^{\infty}\left(\alpha_{n}-k\right)\left(1-\alpha_{n}\right)=\infty,(2.8)$ implies that

$$
\liminf _{n \rightarrow \infty}\left\|x_{n}-T_{[n]}^{s} x_{n}\right\|=0
$$

(IV) Next, we prove the conclusion (4).

Necessity

If $\left\{x_{n}\right\}$ converges strongly to some point $p \in F$, then from $0 \leq d\left(x_{n}, F\right) \leq\left\|x_{n}-p\right\| \rightarrow 0$ as $n \rightarrow \infty$, we have

$$
\liminf _{n \rightarrow \infty} d\left(x_{n}, F\right)=0
$$

\section{Sufficiency}

If $\liminf _{n \rightarrow \infty} d\left(x_{n}, F\right)=0$, it follows from the conclusion (2) that $\lim _{n \rightarrow \infty}$ $d\left(x_{n}, F\right)=0$. Next, we prove that $\left\{x_{n}\right\}$ is a Cauchy sequence in $C$. In fact, since for any $x>0$, $1+x \leq \exp (x)$, therefore, for any $m, n \geq 1$ and for given $p \in F$, from (2.4), we have

$$
\begin{aligned}
\left\|x_{n+m}-p\right\| & \leq\left(1+d_{n+m-1}\right)\left\|x_{n+m-1}-p\right\| \\
& \leq e^{d_{n+m-1}}\left\|x_{n+m-1}-p\right\| \\
& \leq e^{d_{n+m-1}\left[e^{d_{n+m-2}}\left\|x_{n+m-2}-p\right\|\right]} \\
& \leq e^{\left\{d_{n+m-1}+d_{n+m-2}\right\}}\left\|x_{n+m-2}-p\right\| \\
& \leq \cdots \\
& \leq e^{\sum_{j=n}^{n+m-1} d_{j}}\left\|x_{n}-p\right\| \\
& \leq K^{\prime}\left\|x_{n}-p\right\|<\infty
\end{aligned}
$$

where $K^{\prime}=e^{\sum_{j=1}^{\infty} d_{j}}<\infty$. Since

$$
\lim _{n \rightarrow \infty} d\left(x_{n}, F\right)=0
$$

for any given $\epsilon>0$, there exists a positive integer $n_{1}$ such that 


$$
d\left(x_{n}, F\right)<\frac{\epsilon}{2\left(K^{\prime}+1\right)}, \forall n \geq n_{1} .
$$

Hence, there exists $p_{1} \in F$ such that

$$
\left\|x_{n}-p_{1}\right\|<\frac{\epsilon}{\left(K^{\prime}+1\right)} \forall n \geq n_{1} .
$$

Consequently, for any $n \geq n_{1}$ and $m \geq 1$, from (2.11), we have

$$
\begin{aligned}
\left\|x_{n+m}-x_{n}\right\| & \leq\left\|x_{n+m}-p_{1}\right\|+\left\|x_{n}-p_{1}\right\| \\
& \leq K^{\prime}\left\|x_{n}-p_{1}\right\|+\left\|x_{n}-p_{1}\right\| \\
& \leq\left(K^{\prime}+1\right)\left\|x_{n}-p_{1}\right\| \\
& <\left(K^{\prime}+1\right) \cdot \frac{\epsilon}{\left(K^{\prime}+1\right)}=\epsilon .
\end{aligned}
$$

This implies that $\left\{x_{n}\right\}$ is a Cauchy sequence in $C$. Let $x_{n} \rightarrow x^{*} \in C$. Since $\liminf _{n \rightarrow \infty} d\left(x_{n}, F\right)=$ 0 , and so $d\left(x^{*}, F\right)=0$. Again since $\left\{T_{i}\right\}_{i=0}^{N-1}$ is a finite family of $k$-strictly asymptotically pseudocontractive mappings, by Remark 1.1 of [6], it is a finite family of uniformly Lipschitzian mappings. Hence, the set $F$ of common fixed points of $\left\{T_{i}\right\}_{i=0}^{N-1}$ is closed and so $x^{*} \in F$. Thus the sequence $\left\{x_{n}\right\}$ converges strongly to a common fixed point of the family $\left\{T_{i}\right\}_{i=0}^{N-1}$. This completes the proof.

Theorem 2.2: Let $C$ be a closed convex compact subset of a Hilbert space $H$. Let $N \geq 1$ be an integer. Let for each $0 \leq i \leq N-1, T_{i}: C \rightarrow C$ be $N k_{i}$-strictly asymptotically pseudocontraction mappings for some $0 \leq k_{i}<1$ and $\sum_{n=1}^{\infty} r_{n}<\infty$. Let $k=\max \left\{k_{i}: 0 \leq i \leq N-1\right\}$ and $r_{n}=\max \left\{r_{n_{i}}: 0 \leq i \leq N-1\right\}$. Assume that $F=\bigcap_{i=0}^{N-1} F\left(T_{i}\right) \neq \emptyset$. Given $x_{0} \in C$, let $\left\{x_{n}\right\}_{n=0}^{\infty}$ be the sequence generated by an implicit iteration scheme (1.11). Assume that the control sequence $\left\{\alpha_{n}\right\}$ is chosen so that $k<\alpha_{n}<1$ for all $n$. Then $\left\{x_{n}\right\}$ converges strongly to a common fixed point of the family $\left\{T_{i}\right\}_{i=0}^{N-1}$.

Proof: We only conclude the difference. By compactness of $C$ this immediately implies that there is a subsequence $\left\{x_{n_{j}}\right\}$ of $\left\{x_{n}\right\}$ which converges to a common fixed point of $\left\{T_{i}\right\}_{i=0}^{N-1}$, say, $p$. Combining (2.3) with Lemma 1.2, we have $\lim _{n \rightarrow \infty}\left\|x_{n}-p\right\|=0$. Thus $\left\{x_{n}\right\}$ converges strongly to a common fixed point of the family $\left\{T_{i}\right\}_{i=0}^{N-1}$. This completes the proof.

Remark 2.1 Our results extend and improve the corresponding results of Liu [5] and we also extend the iteration process (1.8) of [5] to an implicit iteration process for a finite family of 
mappings.

Received: June 2009. Revised: November 2009.

\section{References}

[1] G.L. ACEDo AND H.K. Xu, Iterative methods for strict pseudo-contractions in Hilbert spaces, Nonlinear Anal. 67(2007), 2258-2271.

[2] F.E. Browder and W.V. Ptryshyn, Construction of fixed points of nonlinear mappings in Hilbert spaces, J. Math. Anal. Appl. 20(1967), 197-228.

[3] K. Goebel and W.A. Kirk, A fixed point theorem for asymptotically nonexpansive mappings, Proc. Amer. Math. Soc. 35(1972), 171-174.

[4] F. Gu, The new composite implicit iterative process with errors for common fixed points of a finite family of strictly pseudocontractive mappings, J. Math. Anal. Appl. 329(2) (2007), 766-776.

[5] Q. LIU, Convergence theorems of the sequence of iterates for asymptotically demicontractive and hemicontractive mappings, Nonlinear Anal. 26(1996), 1835-1842.

[6] M.O. Osilike, Iterative approximation of fixed points of asymptotically demicontractive mappings, Indian J. Pure Appl. Math. 29(12), December 1998, 1291-1300.

[7] M.O. Osilike, Implicit iteration process for common fixed points of a finite family of strictly pseudocontractive maps, J. Math. Anal. Appl. 294(1)(2004), 73-81.

[8] M.O. Osilike And A. Udomene, Demiclosedness principle and convergence results for strictly pseudocontractive mappings of Browder-Petryshyn type, J. Math. Anal. Appl. 256(2001), 431-445.

[9] M.O. Osilike, S.C. Aniagbosor and B.G. Akuchu, Fixed points of asymptotically demicontractive mappings in arbitrary Banach spaces, PanAm. Math. J. 12(2002), 77-78.

[10] S. REICH, Weak convergence theorems for nonexpansive mappings in Banach spaces, J. Math. Anal. Appl. 67(1979), 274-276.

[11] Y. Su AND S. Li, Composite implicit iteration process for common fixed points of a finite family of strictly pseudocontractive maps, J. Math. Anal. Appl. 320(2)(2006), 882-891.

[12] H.K. Xu And R.G. ORI, An implicit iteration process for nonexpansive mappings, Numer. Funct. Anal. Optim. 22(2001), 767-773. 